\title{
Felix qui potuit rerum cognoscere causas
}

\author{
R. Shane Tubbs $\cdot$ Marios Loukas
}

Received: 22 February 2010 / Accepted: 25 February 2010 / Published online: 10 March 2010

(C) Springer-Verlag 2010

It is our distinct pleasure to be involved with the present endeavor provided to the readership of Surgical and Radiologic Anatomy. At the invitation of Editor-in-chief Dr. Fabrice Duparc, we have orchestrated the following offering regarding the clinical anatomy of the nerves of the upper limb (Fig. 1). Proper function of the upper limb is not only imperative in day to day activities but also in allowing man to convey his emotions through gesticulation. Therefore, as morphologists and clinicians, it is our duty to fully understand and continue to research the nervous system of our upper member.

We appreciate the time and expertise of the many authors involved in this current issue that covers a range of topics from imaging of the brachial plexus to landmarks for identifying the brachial plexus and its branches. This international collaboration has been rewarding and we hope, will promote future interactions between anatomists from around the world. It is our hopes that this Special Issue will ignite further research and interest for this anatomical topic.

Guest Editors, Surgical Radiologic Anatomy

R. Shane Tubbs $(\square)$

Pediatric Neurosurgery, Birmingham AL, USA

e-mail: rstubbs@uab.edu

\section{Loukas}

Department of Anatomical Sciences,

St. George's University, Grenada, West Indies

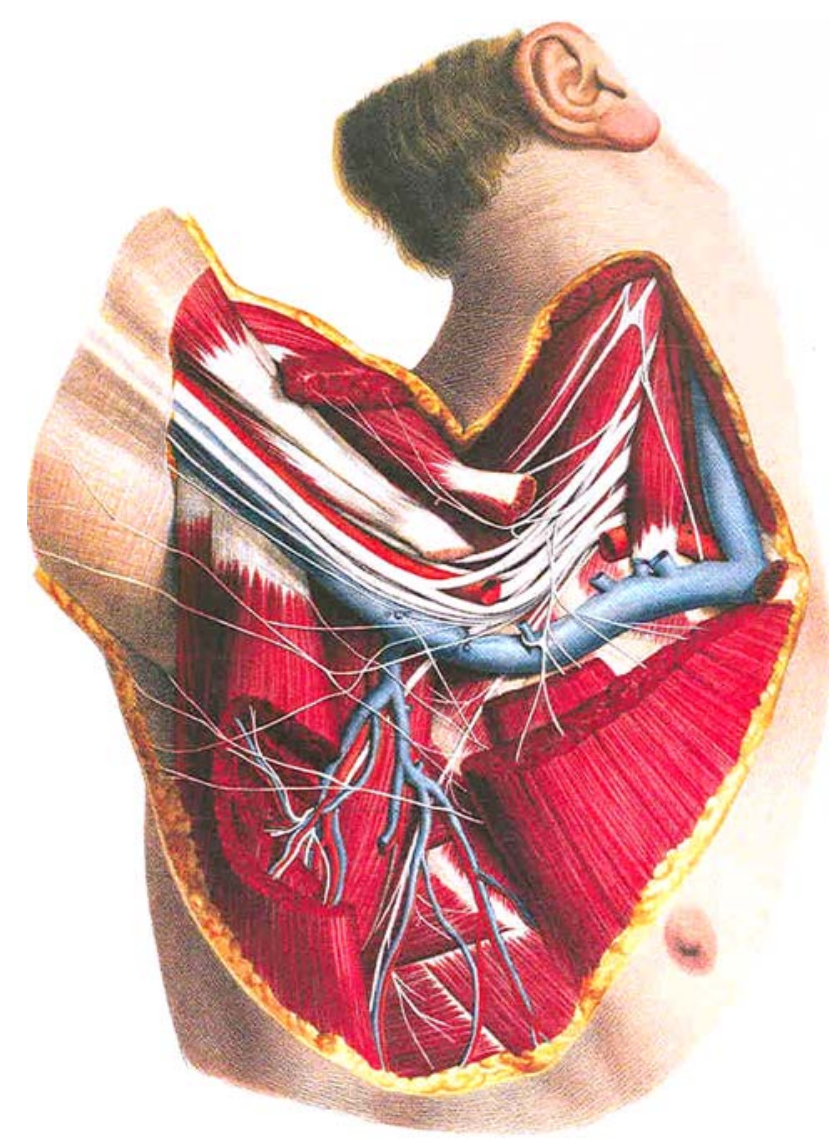

Fig. 1 Drawing of the nerves of the upper limb from Bourgery and Jacob's Atlas of Human Anatomy and Surgery 1831-1854 